\title{
DEMOCRACIA Y JÓVENES, UNA APROXIMACIÓN DESDE LAS COOPERATIVAS
}

\author{
POR
}

\author{
Alberto ATXABAL RADA ${ }^{2}$
}

\section{RESUMEN}

El trabajo aborda las relaciones entre el cooperativismo y los jóvenes y, más concretamente, entre algunos principios cooperativos y los jóvenes. Se incide en las relaciones entre un valor cooperativo y los jóvenes, si bien se puede considerar que se trata de aquel valor que tiene una vinculación más directa con los jóvenes: la democracia. Se destaca la diferente naturaleza de la cooperativa frente a otras formas de empresa por incorporar en su ADN la democracia. Así, la democracia brilla como un valor predicable no ya sólo en la gestión o participación en la empresa cooperativa, sino en su extensión a todos los aspectos de la vida del socio dentro de la sociedad y comunidad a la que pertenece. Este valor debería ser a su vez una vis atractiva para que los jóvenes se acerquen al mundo cooperativo.

Palabras clave: valores cooperativos, democracia, juventud, participación social, gestión empresarial, cooperativas.

Claves Econlit: M140

\section{DEMOCRACY AND YOUNG PEOPLE, AN APPROACH FROM COOPERATIVES}

\begin{abstract}
The paper addresses the relationship between the cooperatives and young people and, more specifically, between some principles of cooperatives and youth. It highlights the relations between one cooperative value and young people, although it can be considered that

\footnotetext{
${ }^{1}$ El presente trabajo se enmarca en la investigación realizada en el seno del proyecto "La difusión de los valores y principios cooperativos entre la juventud" (código A/20130312), financiado por el Gobierno Vasco.

2 Profesor titular de Derecho Financiero y Tributario de la Universidad de Deusto. Dirección de correo electrónico: alberto.atxabal@deusto.es
}

REVESCO No 116 - Tercer Cuatrimestre 2014 - ISSN: 1885-8031 - www.ucm.es/info/revesco

http://dx.doi.org/10.5209/rev_REVE.2014.v116.45716

Fecha de recepción: 19/05/2014

Fecha de aceptación: 02/06/2014 
this is the value which has a direct link with young people: democracy. The different identity of the cooperative stands out from other forms of corporation because they own democracy in their DNA. Thus, democracy shines like a predicable value not only in managing or controlling the cooperative enterprise, but democracy also spreads to all aspects of members' life in society and the community to which members belong. This value should be an attractive turn to approach young people to cooperative world.

Keywords: cooperative values, democracy, young people, membership participation, business management, cooperatives.

\section{INTRODUCCIÓN}

La Asamblea General de las Naciones Unidas proclamaba 2012 Año Internacional de las Cooperativas. A raíz de esta declaración, la Asamblea General de la Alianza Cooperativa Internacional (en adelante, ACI) celebrada en Manchester en octubre de 2012 aprobó un Plan para una Década Cooperativa (Mills y Davies, 2013) que alienta a las cooperativas a involucrar a los jóvenes en el sector para que encuentren allí un espacio para su desarrollo personal y profesional. Las cooperativas deben meditar sobre cómo las perciben los jóvenes, cómo se proyectan ante ellos y cómo comunican con ellos. Garantizar su interés e involucración positiva sólo se puede lograr si se entiende su forma de comunicarse y relacionarse con el uso de la tecnología y los medios sociales. Las relaciones humanas son la razón de ser de las cooperativas. Los jóvenes deben ayudar a moldear la identidad y los mensajes (Mills y Davies, 2013:23). Esta propuesta nos da pie para indagar en los valores cooperativos que atraigan a los jóvenes hacia el movimiento cooperativo. Entre estos valores, la democracia, en concreto, juega un papel convergente como valor diferencial de la cooperativa y como valor ideal de la juventud.

Las cooperativas tienen algo que decir ante la situación económica adversa que afrontamos hoy día. Los recortes de muchos gobiernos en los gastos sociales y públicos han provocado que las desigualdades sigan creciendo a medida que se producen cambios sustanciales en el poder económico. Nos preguntamos si existe alguna alternativa al modelo económico imperante, al modelo capitalista. Las cooperativas pueden aportar un rayo de esperanza y claridad a los ciudadanos de todo el mundo, y a los jóvenes en particular. Podemos seguir preguntándonos: ¿por qué la cooperativa? ¿qué tiene de especial? Entre los distintos modelos de empresa, sólo las cooperativas ponen los recursos económicos bajo el 
control democrático. La cooperativa es la fórmula más auténtica y directa de la aplicación de la democracia en el mundo de la empresa (Divar, 2011:78). El modelo cooperativo es una manera comercialmente eficaz y efectiva de emprender actividades empresariales, que tiene en cuenta una mayor proporción de necesidades humanas y valores en la toma de decisiones. Veamos, pues, qué son las cooperativas y cómo pueden resultar atractivas para los jóvenes de nuestro tiempo.

En primer lugar, analizaré los valores y principios de las cooperativas como elementos definidores de las cooperativas. A continuación, estudiaré las características de las cooperativas como empresa y a su vez como fórmula de participación democrática en la economía. En tercer lugar, abordaré la democracia como valor diferencial de las cooperativas. Para finalizar, desarrollaré la importancia de las cooperativas para los jóvenes, y viceversa, de los jóvenes para las cooperativas, a la luz de la democracia como valor.

\section{LOS VALORES Y PRINCIPIOS DE LAS COOPERATIVAS}

En el Congreso de la Alianza Cooperativa Internacional celebrado en la ciudad de Manchester (Reino Unido) en septiembre de 1995 se aprobó la Declaración sobre la Identidad Cooperativa (ACI, 1996) donde se define por primera vez en la historia de la ACI lo que es una cooperativa ${ }^{3}, \mathrm{y}$ al mismo tiempo enumera los principios y valores cooperativos que quiere promover y salvaguardar la ACI desde sus orígenes, allá por su fundación en 1895, como una guía para las organizaciones cooperativas del siglo XXI. La enumeración de los valores y principios cooperativos pretende ser universal, de tal forma que sirvan para toda cooperativa sin importar lo que hacen ni dónde existen. La Declaración proporciona una base común en la que todas las principales tradiciones cooperativas pueden prosperar y trabajar eficazmente. Se presupone que la existencia de estos valores cooperativos contribuye a diferenciar las cooperativas de otras formas de sociedades o de empresas.

Tal y como afirma la Confederación de Cooperativas del Caribe y Centro América (Escuela Nacional de Educación Cooperativa, 2004) en su Declaración de San Andrés de septiembre de 1995, el movimiento cooperativo debe constituir una alternativa de salida para los hombres y mujeres, para solucionar sus problemas o desajustes del sistema económico

\footnotetext{
${ }^{3}$ Una cooperativa es una asociación autónoma de personas que se han unido de forma voluntaria para satisfacer sus necesidades y aspiraciones económicas, sociales y culturales en común mediante una empresa de propiedad conjunta y de gestión democrática.
} 
social y político que los han mantenido alejados de una vida digna, libre de igualdad y plena de una realización genuina como ser humano.

La resolución que el Consejo de la ACI dirige a la Asamblea General de la ACI para la aprobación de la Declaración sobre la Identidad Cooperativa expresa, entre otras cuestiones, una visión de futuro realizada en 1995 que hoy día conserva toda su validez y aplicación. En concreto, afirma la ACI en dicha resolución que las economías nacionales necesitarán más elementos de independencia, democracia y participación para permitir que las personas tengan más dominio sobre sus vidas económicas y sociales. Por lo tanto, continúa, las cooperativas se volverán incluso más importantes, para más gente, en el futuro. Pueden cumplir su papel histórico de distribuir el poder económico de forma más amplia y justa.

\subsection{Los valores cooperativos}

De la definición de cooperativa, quisiera destacar la referencia a las cooperativas como empresas de propiedad conjunta y de gestión democrática. Esta organización empresarial está basada en unos valores, entre los que brilla la democracia como valor cooperativo (ACI, 1996:17). Estos valores cooperativos, y la democracia entre ellos, son permanentes, están presentes en el movimiento cooperativo desde sus inicios hasta la actualidad. Los valores cooperativos se manifiestan en forma de predicados éticos, de fines últimos, de apelaciones a un sentido moral (Drimer y Kaplan de Drimer, 1981; Trujillo Díez, 2000). O tal y como lo expresa la propia ACI, por debajo de los cambios, hay un respeto fundamental por todos los seres humanos y una creencia en su capacidad de mejorar económica y socialmente mediante la ayuda mutua (ACI, 1996:23).

Sin embargo, en el Informe que acompaña a la Declaración sobre la Identidad Cooperativa no se hace referencia a la democracia como valor, y sí lo hace respecto a los demás valores. Como afirma Martínez Charterina (1995:44), el valor de la democracia queda reflejado perfectamente en el principio de la gestión democrática por parte de los socios, y es en el comentario a dicho principio donde se realizan las consideraciones de derechos y responsabilidades que implica la democracia en las cooperativas, y también el sentido más amplio que supone el fomento del espíritu de la democracia en las cooperativas como algo esencial. Volveremos sobre estas ideas. 


\subsection{Los principios cooperativos}

Como nos dice la propia ACI en su Declaración sobre la Identidad Cooperativa, estos valores se ponen en práctica a través de siete principios cooperativos, que son pautas o reglas de funcionamiento de las cooperativas. No basta con conocer si la cooperativa sigue la letra de los principios, sino que también ha de saberse si sigue el espíritu de los mismos. Los principios, además, no son independientes, sino que están unidos, de forma que cuando no se atiende a uno de ellos todos se resienten (Martínez Charterina, 1995:38).

Son mandatos que proporcionan normas de conducta. Como tales reglas de funcionamiento son cambiantes, mutables, se adaptan a las circunstancias de cada momento. Son principios prácticos en sí mismos, y por consiguiente, flexibles, aplicables con diferente grado de detalle en diferentes tipos de cooperativas en distintas situaciones. Son principios que requieren que los cooperativistas tomen decisiones sobre la naturaleza de la democracia de sus instituciones, o la distribución de los excedentes creados, entre otras cuestiones.

En particular, la democracia como valor se concreta en el segundo principio que se refiere a la gestión democrática por parte de los socios y en el tercer principio relativo a la participación económica de los socios. Si bien el cuarto principio ${ }^{4}$ también aplica indirectamente la democracia como valor, cuando exige que los socios deben mantener el control democrático de la cooperativa cualesquiera que sean los acuerdos que se firmen con otras organizaciones o gobiernos, e independientemente de las fuentes de financiación externa de la cooperativa.

Estos valores y principios expresan la identidad de las cooperativas por lo que las cooperativas deben incluirlos en sus normativas o reglamentos, ponerlos en práctica en su trabajo diario y animar a sus gobiernos a basar la legislación cooperativa en ellos. Como afirma Gómez Urquijo (1998:110), estos valores son un medio de expresar las actitudes necesarias para culminar la aspiración de perfección de la sociedad y del individuo que persigue el movimiento cooperativo y la ACI en particular. La prevalencia de estos valores para los cooperativistas les obliga a difundirlos dentro y fuera del movimiento cooperativo. Así, el quinto principio cooperativo les obliga a las cooperativas a informar al gran público, y

\footnotetext{
${ }^{4}$ El cuarto principio cooperativo proclama al autonomía y la independencia de la cooperativa en los siguientes términos: "Las cooperativas son organizaciones autónomas de autoayuda, gestionadas por sus socios. Si firman acuerdos con otras organizaciones, incluidos los gobiernos, o si consiguen capital de fuentes externas, lo hacen en términos que aseguren el control democrático por parte de sus socios y mantengan su autonomía cooperativa".
} 
especialmente a los jóvenes y a los líderes de opinión, de la naturaleza y beneficios de la cooperación.

\section{LA DEMOCRACIA COMO VALOR COOPERATIVO}

La democracia como valor cooperativo nos obliga a replantearnos las grandes preguntas que preocupan a los seres humanos: ¿Cuáles son los límites de la democracia? ¿Cómo pueden organizar los hombres y las mujeres sus sociedades de forma que sean más equitativas? ¿Cómo se puede cambiar la economía de forma que sea eficaz y ética a un tiempo? ¿Cuáles son las reivindicaciones justas de los trabajadores? ¿Cómo hay que remunerar al capital? ¿Cómo se puede organizar la economía para producir bienes suficientes a precios justos y con buena calidad para cumplir con las necesidades de todo el mundo? ¿Cómo se pueden construir mejores comunidades? Las cooperativas y los cooperativistas no pueden resolver todos estos interrogantes solos, pero pueden ayudar mucho en hacerlo. Y las cooperativas de trabajo asociado, con mayor motivo, porque llevan dentro de sus estructuras y filosofías algunas de las respuestas más persuasivas a una de las grandes preguntas planteadas por la industrialización: ¿cómo asegurar que los trabajadores disfruten de la dignidad a la que su trabajo les da derecho?

Por ejemplo, la perspectiva de la cooperativa de trabajo también fomenta el hecho de que otros tipos de cooperativas consideren con más cuidado cómo ven y cómo tratan a sus empleados. Sugiere la necesidad de capacitar a los empleados de forma que sean aceptables dentro de las cooperativas existentes para darles más responsabilidades, para escuchar mejor lo que sugieren, para recompensarles en la medida apropiada y para buscar formas en las que podrían invertir en sus cooperativas. Sugiere la necesidad de reconsiderar los estilos de gestión dentro de muchas cooperativas, estilos que normalmente tomaron elementos sin crítica de la empresa capitalista; invita a otras cooperativas a considerar cómo mejor pueden capacitar a sus empleados, lo que constituye un determinante cada vez mayor del éxito económico (ACI, 1996:131).

La democracia es uno de los valores consustanciales a la naturaleza de las cooperativas, desde una doble dimensión: hacia dentro de la cooperativa, donde la propiedad, el control y la gestión de las cooperativas se lleva a cabo por los socios de manera democrática; y hacia afuera de la cooperativa, donde el socio cooperativista participa en la economía y organiza los factores de producción a través de una empresa basada en la persona 
y no en el capital. En palabras de la ACI (1996:53), el fomento de este espíritu democrático es una tarea sin fin, difícil, valiosa e incluso esencial.

Además, la democracia es el incentivo para participar en la cooperativa (Marcus, 1988): una cooperativa no puede ser gobernada por unos pocos, no sólo por hombres dejando sin decisión a las mujeres, si bien la falta de democracia plena sigue siendo uno de los defectos más importantes que se producen en las cooperativas. Las cooperativas no pueden ser controladas por un solo socio o una minoría de socios. Todos los socios tienen derecho a controlar la cooperativa y la democracia como valor encarna este derecho para hacerlo efectivo.

Para Birchall (2005:3) y Somerville (2007:8), la democracia es un valor clave del que derivan directamente principios cooperativos. La democracia implica el control democrático por parte de los asociados, y junto a la equidad, permite diferenciar a la cooperativa de otras formas de empresa. Si podemos encontrar una forma de hacer negocios que recompense equitativamente a la gente, podremos distribuir los frutos de la actividad económica de forma tal que no genere desigualdades. Los negocios equitativos son democráticos y reducen la necesidad de que los gobiernos intervengan para corregir las desigualdades.

La democracia se incardina principalmente en dos principios, a saber, el principio de gestión democrática y el principio de participación económica de los socios.

\subsection{El principio de gestión democrática}

El principio de gestión democrática es, por tanto, un principio que goza de notable importancia, sobre todo, para las cooperativas integradas mayoritariamente por socios trabajadores (Del Burgo, 2002:59). Si la persona es libre y los socios de una cooperativa son personas, se debe permitir a todos ellos participar en la cooperativa con idéntica libertad y capacidad de decisión. Se diferencia así de manera sustancial de la sociedad capitalista. En la cooperativa se pretende que, mediante una gestión democrática, la persona se sienta perfectamente integrada e identificada con la empresa en la que trabaja (Alonso Rodrigo, 2001:30). Es el caso, por ejemplo, de las cooperativas del Grupo Mondragón que son, en su mayoría, cooperativas de trabajo asociado o de producción. La unidad básica de la cooperativa es el socio, que generalmente es un individuo. Esta fundamentación en la persona humana es una de las principales características que distingue a una cooperativa de las empresas orientadas principalmente en beneficio del capital. 
Pero no debemos olvidar que la cooperativa es una empresa en el sentido de que es una entidad organizada que funciona en el mercado $y$, por tanto, debe servir a sus socios de manera eficaz y eficiente. Desde esta perspectiva, los socios representantes encargados de la gestión de las cooperativas mantienen sus puestos en fideicomiso para el beneficio inmediato y a largo plazo de los socios (ACI, 1996:53). Las cooperativas no pertenecen a los dirigentes elegidos más de lo que pertenecen a los empleados que están bajo sus órdenes. Los dirigentes, por tanto, responderán de sus acciones ante los socios durante su mandato.

Por otro lado, no es difícil ver cómo el valor de la democracia entre los socios exige cierto tipo de estrategia en las relaciones entre ellos, una política sobre la distribución de la información, y así sucesivamente. Los socios tienen el derecho de participación ${ }^{5}$, el derecho de ser informados, el derecho de ser escuchados, y el derecho de estar involucrados en la toma de decisiones. Esa democracia en la gestión se manifiesta en el reparto de los votos: un socio, un voto, en las cooperativas de primer grado.

Esta regla de un voto para cada socio está siendo socavada por el marco legislativo de las cooperativas cuando se introduce un voto ponderado en las cooperativas de primer grado. La implantación del voto plural ponderado, en función de la actividad cooperativizada y para las cooperativas de primer grado es una opción reconocida por todas las legislaciones autonómicas de cooperativas, si bien se limita en función del tipo de socio y la clase de sociedad cooperativa (Buendía Martínez, 2000:10).

Igualmente, la aplicación práctica de estos derechos de una manera equitativa se torna, a veces, una tarea difícil en las grandes cooperativas o en las cooperativas de segundo o ulterior grado. Además, la necesidad de las sociedades cooperativas de acceder al crédito ha llevado al legislador a regular la posibilidad de que la toma de decisiones sea proporcional al capital suscrito por socios capitalistas de la cooperativa como en el caso de las sociedades cooperativas mixtas ${ }^{6}$, que supone otra distorsión del principio democrático de participación (Buendía Martínez, 2000:11-12; Del Burgo, 2002:83-85; Trujillo Díez, 2000:1350).

\footnotetext{
${ }^{5}$ En algunas leyes cooperativas el socio es incluso obligado a participar bajo la sanción de su exclusión de la cooperativa; otras leyes menos rígidas tratan de establecer instrumentos concretos para hacer la participación del socio, aunque indirecta, más efectiva, por ejemplo, las asambleas sectoriales o las asambleas virtuales.

${ }^{6}$ Véanse el artículo 107 de la Ley estatal 27/1999, de 16 de julio, de Cooperativas y el artículo 136 de la Ley 4/1993, de 24 de junio, de Cooperativas de Euskadi. En estas sociedades cooperativas mixtas, el socio capitalista puede tener hasta el $49 \%$ del voto en la Asamblea.
} 
Ello no obstante, la cooperativa es una empresa de propiedad conjunta y de gestión democrática. En las cooperativas el control se distribuye entre los socios sobre una base democrática y es un elemento diferenciador respecto a las empresas capitalistas o las organizaciones controladas por los gobiernos. La prevalencia de la persona sobre el capital es una consecuencia inmediata y directa de los principios jurídicos de democracia y participación.

\subsection{El principio de participación económica de los socios}

Las cooperativas funcionan de forma que el capital es el sirviente y no el amo de la organización. Sin duda, la subordinación del capital en la cooperativa se pone de manifiesto a través del interés limitado al capital (Martínez Charterina, 1996:221). A diferencia de la sociedad capitalista, la cooperativa no concede al capital derecho político alguno. El capital es un mero instrumento para la consecución del fin social de la cooperativa: claro ejemplo del carácter personalista de la sociedad cooperativa. Sin embargo, las figuras del socio colaborador de la Ley 27/1999, de 16 de julio, de Cooperativas, o del socio inversor no usuario han permitido la entrada de inversores capitalistas en los órganos societarios de la cooperativa, desnaturalizando su esencia, y llegando a controlarla (Kaplan de Drimer, 2000:168-171; Del Burgo, 2002:67-70).

Evidentemente, los socios deben aportar un capital a la cooperativa para adquirir tal condición. Con el fin de preservar la naturaleza democrática de la empresa, se espera de los socios de las cooperativas que contribuyan de forma equitativa con capital y controlen democráticamente el capital de ésta. Para mantener la creencia de que la fortaleza de la cooperativa procede de compartir los recursos para generar autoayuda, existe la suposición subyacente de que todos los socios deberían poseer una porción del capital de las cooperativas (Hoyt, 1996: 18-22).

También conviene señalar que la cooperativa se define como una empresa cuya propiedad es ejercida democráticamente. Esto quiere decir que los cooperativistas pueden ser individualmente propietarios de las partes que han suscrito, pero no son propietarios de forma individual de la cooperativa o de su activo. Se observa así la diferencia entre el valor de una parte de la cooperativa y el valor de una acción de una sociedad de capitales (Bancel, 2014).

La prevalencia de la persona sobre el capital, latente en la democracia como valor, se ha plasmado en la igualdad de los derechos de voto de todos los socios. Un socio, un voto. El 
baremo para medir la participación en la cooperativa no viene determinado por la cantidad de capital aportada, sino que se concede el mismo valor a la opinión de todas las personas, independientemente del volumen de su participación en el capital.

Esta máxima se ha querido trasladar a la participación económica de los socios en el capital aunque no resulta de fácil aplicación en aquellas cooperativas que adquieren una cierta dimensión porque las leyes del mercado presionan para que los puestos más cualificados sean retribuidos por encima de los demás. Por ejemplo, en las cooperativas de trabajo asociado las diferencias salariales no son tan abismales como en las empresas capitalistas. Es la llamada solidaridad retributiva (Del Burgo, 2002:60). Pero ello no impide a que haya una relación que se ha ido incrementando de 1 a 3 , de 1 a 4 o de 1 a 5 entre los socios que más reciben por sus operaciones en la cooperativa frente a los que menos reciben.

Este capital se gestiona de manera democrática. De ordinario, los socios reciben una compensación, si la hay, limitada sobre el capital entregado. Los excedentes de la actividad se pueden destinar al desarrollo de la propia cooperativa, constituyendo reservas en parte irrepartibles, al beneficio de los socios en proporción a sus operaciones con la cooperativa, y al apoyo de otras actividades aprobadas por los socios, por ejemplo, el apoyo a otras empresas comunitarias u otras cooperativas asociadas o al desarrollo del movimiento cooperativo a todos los niveles.

La primera de las posibilidades, en muchas cooperativas, debería ser la forma normal de asignar los excedentes no devueltos a los socios, y es de vital importancia para la viabilidad a largo plazo de la cooperativa (ACI, 1996:57). Ahora bien, En el Congreso de la ACI de Manchester de 1995 ya no se le da carácter obligatorio a que parte de las reservas que se doten con los excedentes puedan ser indivisibles, lo que sin duda reforzaría la necesidad de capitalizar las cooperativas, sino que se deja una cláusula abierta permitiendo esta posibilidad (Martínez Charterina, 1996:221).

La segunda de las posibilidades, esto es, el reparto de los beneficios entre los socios en proporción a las operaciones realizadas con la cooperativa, y no al capital aportado, constituye otro tradicional elemento diferenciador respecto a la empresa capitalista.

En definitiva, los socios contribuyen equitativamente al capital de sus cooperativas y lo gestiona de forma democrática. Por lo menos parte de ese capital es normalmente 
propiedad común de la cooperativa. Usualmente, los socios reciben una compensación, si la hay, limitada sobre el capital entregado como condición para ser socio.

\section{LA COOPERATIVA, COMO FÓRMULA DE PARTICIPACIÓN DEMOCRÁTICA EN LA ECONOMÍA}

La cooperativa aporta al socio un elemento adicional que excede el ámbito puro empresarial. La cooperativa permite al socio una fórmula democrática para participar en la economía y en la sociedad. No hay que olvidar la pretensión del cooperativismo de mejorar las condiciones de vida del socio y aumentar su bienestar, pero al mismo tiempo se quiere conseguir la transformación de la sociedad a través de la transformación de la persona (Gómez Urquijo, 1998:105). Se desarrolla de esta manera el sentido social y el sentido de la comunidad con lo que se favorece la solidaridad y la paz entre los hombres, en definitiva, se camina hacia el logro de unos elevados ideales para un mundo mejor. Ahí es donde brilla un valor como la democracia, predicable no ya sólo en la gestión o participación en la empresa cooperativa, sino en su extensión a todos los aspectos de la vida del socio a nivel social y como miembro de una comunidad más amplia.

Desde este punto de vista, como afirma Divar (2013:74), puede sostenerse que tanto las empresas cooperativas como el movimiento cooperativo en su conjunto, son partícipes de un movimiento de reforma social y democrática. Estas empresas se distinguen de las empresas capitalistas por el sentido de su misión (Hesselbach, 1978:151). Persiguen la realización de sus objetivos tomando a su cargo ciertas actividades adicionales en representación de la comunidad y del interés común.

Se puede afirmar que una empresa regida por el valor democrático constituye un elemento que promueve el desarrollo y la formación de la persona, y remueve los obstáculos de naturaleza económica o social que de hecho impiden la participación efectiva de los ciudadanos más débiles en la vida económica y política. En otras palabras, las cooperativas son instrumentos de democracia económica porque permiten a todos, también a los sin capital, tomar parte en la vida económica y social del país.

Esta conclusión, no obstante, se encuentra en entredicho. La degradación progresiva de los fenómenos democráticos, debido a la influencia de procesos de utilidad, pragmatismo, tecnificación y especialización, ha provocado el desinterés y la dejación con respecto a los valores participativos en la vida pública, lo que ha generado un desapego creciente por la 
participación en la vida política. Esta situación se ha trasladado a los ámbitos económicos a partir de ciertas estructuras de poder, donde la democracia pasa a ser de delegación y representación con la consiguiente jerarquización y burocratización (Divar, 2013:70).

Pero admitiendo ello, persiste en las sociedades avanzadas una desconfianza mayor hacia los valores económicos dominantes, provocándose reacciones frente a las carencias del capitalismo o de la gestión económica púbica. El capitalismo se ha mostrado incapaz de asegurar un armonioso desarrollo de la economía y de alcanzar la justicia distributiva. Por ello, para coadyuvar con la participación democrática, y al efecto de ir paulatinamente hacia una economía democrática y social, se arguye la necesidad de retomar formas empresariales basadas en la solidaridad económica (Divar, 2013:71).

\section{LOS JÓVENES Y LAS COOPERATIVAS}

Como hemos dicho anteriormente, la preocupación por la persona, por el socio es uno de los ejes del movimiento cooperativo desde sus orígenes. Esta preocupación por la persona no puede quedar limitada al interior de la cooperativa. Necesariamente, esta actitud de respeto hacia unos valores que se genera dentro de ella ha de traslucirse fuera y extenderse a los no miembros, y entre ellos a los jóvenes.

La involucración de los jóvenes en las cooperativas se produce, principalmente, por dos vías (Smith, Puga y MacPherson, 2006:243): en primer lugar, mediante la creación de cooperativas por los jóvenes, y en segundo lugar, a través de los esfuerzos de las cooperativas ya establecidas para alentar la participación juvenil.

Además, los valores del sistema cooperativo (y, entre ellos, la existencia de una auténtica democracia participativa) son eficaces para alcanzar, junto al económico, otros objetivos de orden personal como la autoestima, la autorrealización o incluso para encontrar sentido a la existencia. Como afirma Gadea (2011:14), en nuestras sociedades, la condición de identidad colectiva plantea tantos problemas como la condición de necesidad. El ideario cooperativista puede contribuir a marcar las pautas de un estilo de vida más satisfactorio y más pleno, cuestión que también interesa a los jóvenes.

\subsection{La ACI y los jóvenes}

Los jóvenes han estado presentes en el movimiento cooperativo desde sus orígenes, de hecho, entre los 28 pioneros de Rochdale sólo uno era mayor de 30 años. Pero será a partir de 
la creación en los años 50 del siglo pasado de la Federación Internacional de Jóvenes Cooperativistas, cuando la ACI y el movimiento cooperativo empiecen a ser conscientes de que debe darse a la juventud un papel mayor en el movimiento y de la necesidad de formar a los jóvenes como un reto del futuro.

La Alianza Cooperativa Internacional (1996:95) quiere atraer a los más jóvenes hacia el mundo cooperativo, como garantía del éxito de sus postulados y del relevo de los actuales socios cooperativistas. Afirma la ACI (1996:107) que gran parte de la vitalidad del movimiento cooperativo se obtendrá de la implicación de los jóvenes. En opinión de Martínez Charterina (1996:223), la presencia de las cooperativas en la sociedad y su aspiración de conquista en la convicción de la bondad del sistema, exigen que se difunda el mismo a la sociedad en general, y a los jóvenes en particular.

El Plan para una Década Cooperativa de la ACI promueve centrarse específica y directamente en los jóvenes adultos y jóvenes en general, estudiando sus mecanismos para crear y mantener relaciones, y considerando si pueden y deben adaptarse los mecanismos tradicionales de participación y relación. ¿Elaboran las jóvenes generaciones sus propios mecanismos de colaboración, de los cuales puede aprender un sector cooperativo establecido, hasta posteriormente adoptarlos? ¿Están ofreciendo las cooperativas los puntos de acceso más indicados para los jóvenes? ¿Están dispuestas a crear un espacio o plataforma para ellos y que les permita moldear el futuro? ¿Están usando tan siquiera el lenguaje apropiado?

La ACI es consciente de que para atraer a los jóvenes hay que presentar el movimiento cooperativo como una forma de empresa suficientemente atractiva para ellos donde se les ofrecen posibilidades de futuro. Para ello, la ACI quiere destacar aquello que tiene de particular una cooperativa, su aspecto idealista y su faceta de preocupación social. Los principios y valores cooperativos aparecen así, como la principal forma de conexión con los jóvenes, que podrían encontrar la respuesta a sus ideales de un mundo mejor, una causa por la que merezca la pena luchar y trabajar (Watkins, 1929). No obstante, los jóvenes de hoy no son los de hace cuarenta años, y los valores de los jóvenes van cambiando con el tiempo. Se puede hablar también de los contravalores o valores negativos de los jóvenes, como la dificultad que tienen para adoptar compromisos duraderos o la prevalencia del individualismo sobre los valores solidarios ${ }^{7}$. Del mismo modo, hay jóvenes que prefieren una mayor

\footnotetext{
${ }^{7}$ Elzo, Javier, "Cómo son los jóvenes a quienes orientamos", intervención en el VI Encuentro Estatal de Orientación, Universidad de Deusto, 12 de mayo de 2012.
} 
participación en otros grupos voluntarios basados en causas comunes, como ecología, bienestar y actividades del tiempo libre. Ahora bien, tampoco todos los jóvenes son iguales ni todos acabarán siendo cooperativistas. Evidentemente, un joven se acercará al mundo cooperativo en la medida en que su escala de valores se asemeje a los valores de las cooperativas.

El cooperativismo aparece también como una adecuada solución a los problemas de la juventud. La aspiración del movimiento cooperativo a mejorar la sociedad y a construir un mundo mejor bajo ideales de paz, igualdad y democracia, es sin duda, una importante contribución a los intereses de los jóvenes y a sus condiciones de vida y futuro. La aspiración a lograr un mundo mejor no es algo anecdótico en el movimiento cooperativo, sino que tiene un papel esencial como meta final. La propia Alianza Cooperativa Internacional impulsa desde época muy temprana el logro de un nuevo orden social y la importancia de ayuda para todos los necesitados a través del cooperativismo (Gómez Urquijo, 1998:101-103 y 279).

\subsection{La consecución de un empleo a través de las cooperativas}

Hay temas de justicia social como la situación de los jóvenes en el mercado de trabajo, que las cooperativas han intentado solucionar históricamente y que deben seguir haciéndolo. En muchos países del sur hay un excedente de hombres y mujeres jóvenes en busca de empleo y preocupados por cómo van a organizar sus vidas. En la mayoría de los países del norte, las oportunidades de pleno empleo se desdibujan cada día ${ }^{8}$. Muchos jóvenes se enfrentan, por consiguiente, a futuros empobrecidos y oportunidades limitadas. La cooperativa les ofrece una alternativa basada en valores como la democracia, y en la prevalencia de la persona sobre el capital.

En un mundo cada vez más globalizado, las cooperativas ofrecen su capacidad histórica de reducir las divisiones sociales y económicas de forma equitativa, por lo menos para los que tienen alguna capacidad de controlar sus vidas. Igual que siempre han hecho en el pasado, las cooperativas ofrecen oportunidades para que la gente se ayude a sí misma. La primera forma en que las cooperativas contribuyen a la erradicación de la pobreza es generando empleo, tanto directo como indirecto. Este aspecto, que fue esencial en el origen y nacimiento del movimiento cooperativo, sigue siendo de vital interés en el momento actual en el que el principal problema de muchas economías continúa siendo el paro. Y esta opción

\footnotetext{
${ }^{8}$ En España el paro juvenil ronda el $60 \%$ de la población activa juvenil, mientras que en la Comunidad Autónoma Vasca dicha cifra se acerca al $40 \%$.
} 
debería ser lo suficientemente atractiva para cautivar a los más jóvenes en el momento en que les corresponde entrar en ese mercado global. Por ejemplo, en Serbia hay cooperativas que buscan familiarizar a los jóvenes desocupados con el mundo del trabajo a través de la provisión de puestos de empleo de corto plazo. Aproximadamente, un 30\% de aquellos que encuentran un empleo de corto plazo a través del sistema de cooperativas logran posteriormente un empleo permanente (Smith, Puga y MacPherson, 2006:126-127).

Las cooperativas son una excelente contribución al problema del paro, con la ventaja de que no sólo facilitan una forma de trabajo a los jóvenes, sino que lo hacen precisamente estimulando su iniciativa, autoayuda y trabajo responsable. Mejora su situación económica pero también lo hace su situación social, en lo que contribuyen decisivamente los esfuerzos de las cooperativas en la educación, ofreciéndoles unos valores y unos principios para su formación integral.

\subsection{La formación y educación de los jóvenes}

Otro objetivo del movimiento cooperativista hacia los jóvenes va dirigido a su formación y educación. El cooperativismo aparece como el medio idóneo de educar a los jóvenes porque forma en valores humanos de democracia, solidaridad y altruismo. Pero, por otro lado, una juventud formada es una garantía de eficacia para la cooperativa en la que se integra. La ACI, consciente de la falta de atractivo del cooperativismo entre los jóvenes, viene predicando desde los años 60 del siglo pasado la necesidad de formar jóvenes utilizando formas de expresión y educativas propias de los jóvenes, adaptándose a los cambios tecnológicos, sociales y culturales de la juventud. Esta preocupación se acaba plasmando en el quinto principio de la Declaración sobre la Identidad Cooperativa aprobada en el Congreso de la ACI de Manchester de 1995, según el cual las cooperativas informan al gran público, especialmente a los jóvenes y a los líderes de opinión, de la naturaleza y beneficios de la cooperación.

No obstante, el camino no está exento de obstáculos. Precisamente, el desconocimiento de esta figura jurídica es uno de los motivos por los que los jóvenes emprendedores no eligen las cooperativas para iniciar una actividad económica. Tal vez unos conocimientos sobre cooperativas posibilitarían la constitución de las mismas por los jóvenes, más teniendo en cuenta que gran parte de la juventud comparte valores democráticos, solidarios y participativos. 
Hay algunos países que han impulsado la creación de cooperativas por jóvenes estudiantes (Smith, Puga y MacPherson, 2006:115). Esta innovadora forma de aprendizaje nació hace tiempo en la Universidad de Jyväskylä (Finlandia) y se aplica con éxito en varios países del mundo. Por ejemplo, en Finlandia existen las Team Learning Cooperatives o en el País Vasco donde se han puesto en marcha las Junior Cooperativas ${ }^{9}$. En el caso vasco, la figura resultante deberá llevar en el nombre de la empresa la palabra "junior" y tendrá la característica de que crearán empresas reales a todos los efectos. Para ello bastará con notificarlo al registro de cooperativas. Al concluir los estudios, pasarán a ser cooperativas de trabajo al uso.

\subsection{La participación de los jóvenes en la cooperativa}

Las cooperativas responden asimismo a otro problema de la juventud: su falta de participación y acceso a puestos de responsabilidad, y lo solucionan por su forma de concebir la participación democrática de los socios en la empresa. Los jóvenes pueden establecer objetivos acorde con sus inquietudes y habilidades, además de participar en la toma de decisiones y ser protagonistas de un proyecto colectivo gestionado de manera democrática. La participación de los jóvenes en la dirección de las cooperativas permitiría hacer más atractivas las cooperativas para los jóvenes porque éstos sabrán potenciar aquellos aspectos que les resultan más interesantes, pero al mismo tiempo se trata de educar a los jóvenes hacia la responsabilidad, ejercitando tal responsabilidad. El movimiento cooperativo quiere huir de la formación de cooperativas compuestas estrictamente por jóvenes y promueve la integración global en cooperativas con socios de cualquier edad (Böök, 1992:204). Aquí nuevamente, la democracia adquiere toda su plenitud como valor cooperativo para que la integración de los jóvenes lo sea en pie de igualdad, evitando que las jerarquías de edad entre los socios impidan la integración y la asunción de responsabilidades por los más jóvenes.

\footnotetext{
${ }^{9}$ Dentro del Programa de Reactivación del empleo 2013-2014, el Gobierno Vasco en su iniciativa de impulsar el emprendimiento y el fomento del empleo juvenil ha dado forma jurídica a la creación de cooperativas en el ámbito educativo con las Junior Cooperativas, en colaboración con Mondragón Unibertsitatea. La nuevas cooperativas estarán formadas por equipos de estudiantes de entre 10 y 20 personas. Se constituirán al inicio de sus estudios como asociaciones, para formar luego, con la ayuda del programa del Gobierno, cooperativas de Trabajo Asociado Junior. Su finalidad será impulsar el desarrollo de proyectos reales para poner en práctica los conocimientos teóricos adquiridos (creación, organización y gestión de una cooperativa, desarrollo de una actividad en forma cooperativa y colaborativa...). Así, las empresas constituidas al amparo de planes formativos y emprendedores de alguna universidad radicada en Euskadi recibirán el 85\% del coste neto de la actividad, con un límite de 5.000 euros por entidad beneficiaria. Las cooperativas junior beneficiadas en 2013 se pueden consultar en la Resolución de 24 de febrero de 2014, de la Directora de Economía Social, por la que se hace pública la relación de entidades beneficiarias de las ayudas previstas en la Orden de 1 de agosto de 2013 por la que se convocan y regulan ayudas para la Formación en la Economía Social. BOPV, núm. 60, de 27 de marzo de 2014.
}

REVESCO Nº 116 - Tercer Cuatrimestre 2014 - ISSN: 1885-8031 - www.ucm.es/info/revesco 


\section{CONCLUSIONES}

En definitiva, la democracia como valor cooperativo permite diferenciar a las cooperativas del resto de organizaciones económicas, puesto que los demás valores cooperativos, de forma explícita o implícita, podrían ser asumidos por las empresas capitalistas convencionales. La estructura de las cooperativas plasma la democracia como norma de comportamiento y característica diferencial del resto de empresas. La democracia se incardina principalmente en dos principios, a saber, el principio de gestión democrática y el principio de participación económica de los socios.

Este valor, consustancial a la naturaleza de las cooperativas, se despliega desde una doble dimensión: hacia dentro de la cooperativa, como hemos dicho, donde la propiedad, el control y la gestión de las cooperativas se lleva a cabo por los socios de manera democrática; pero también hacia afuera de la cooperativa, donde el socio cooperativista participa en la economía y organiza los factores de producción a través de una empresa basada en la persona y no en el capital. En este sentido, la participación económica de los socios cooperativistas produce una auténtica sociedad democrática. La democracia económica se traslada a la democracia política. Esta dimensión externa se refleja en la extensión de los valores cooperativos, y entre ellos la democracia, a los no miembros y a los jóvenes, en particular.

La Alianza Cooperativa Internacional y el movimiento cooperativo quieren atraer a los más jóvenes hacia el mundo cooperativo, como garantía del éxito de sus postulados y del relevo de los actuales socios cooperativistas. Además, el cooperativismo aparece también como una adecuada solución a los problemas de la juventud. La aspiración del movimiento cooperativo a mejorar la sociedad y a construir un mundo mejor bajo ideales de paz, igualdad y democracia, es sin duda, una importante contribución a los intereses de los jóvenes y a sus condiciones de vida y futuro.

La involucración de los jóvenes en las cooperativas se produce, principalmente, por dos vías: en primer lugar, mediante la creación de cooperativas por los jóvenes, y en segundo lugar, a través de los esfuerzos de las cooperativas ya establecidas para alentar la participación juvenil. De esta forma, se mejora su situación económica pero también lo hace su situación social, en lo que contribuyen decisivamente los esfuerzos de las cooperativas en la educación, ofreciéndoles unos valores y unos principios para su formación integral. 
Así, el cooperativismo aparece como el medio idóneo de educar a los jóvenes porque forma en valores humanos de democracia, solidaridad y altruismo. Pero, por otro lado, una juventud formada es una garantía de eficacia para la cooperativa en la que se integra. Conjugando ambas pretensiones, la de acercar a los jóvenes a las cooperativas y la de formarles en los valores cooperativos, se han impulsado la creación de cooperativas por jóvenes estudiantes, como las Junior Cooperativas en el País Vasco.

Por último, las cooperativas también permiten, con mayor facilidad que otras formas de empresa, que los jóvenes puedan participar en la toma de decisiones y ser protagonistas de un proyecto colectivo gestionado de manera democrática.

En definitiva y utilizando las palabras de la ACI (1996:131), por razones tanto económicas como de justicia, las cooperativas tienen una obligación para llegar de forma consciente y continua a los jóvenes. De modo algo tópico pero también significativo, el futuro del movimiento cooperativo está con los jóvenes. Las tradiciones ricas y diversas del movimiento, los matices y el potencial de sus filosofías, necesitan ser reconsiderados y reaplicados por cada generación. Cuanto antes se impliquen los jóvenes, cuanto antes comiencen a pensar ellos mismos cómo debería ajustarse el movimiento cooperativo a su época, será mejor para todos. El dialogo a través de las generaciones de los cooperativistas es un requisito fundamental para el continuo éxito de las cooperativas.

\section{BIBLIOGRAFÍA}

ALIANZA COOPERATIVA INTERNACIONAL (1996) Declaración de la Alianza Cooperativa Internacional sobre la identidad cooperativa. Los principios cooperativos. Vitoria-Gasteiz: Consejo Superior de Cooperativas de Euskadi.

ALONSO RODRIGO, E. (2001) Fiscalidad de cooperativas y sociedades laborales. Barcelona: Generalitat de Catalunya.

BANCEL, J.L. (2014) Tercer principio: contribución económica de los socios. En Guías orientativas de la Comisión de Principios de la ACI, en http://ica.coop/sites/default/files/attachments/DRAFT\%20Guidance\%20Notes\%20P3\%2C \%20P5\%2C\%20P7\%20Spanish\%202014-02-11.pdf.

BIRCHALL, J. (2005) Los principios cooperativos, diez años después. Revista de la Cooperación Internacional, $\mathrm{N}^{\mathrm{o}}$ 2, p. 1-16.

BÖÖK, S.Å. (1992) Valores para un mundo en cambio. San José de Costa Rica: ACI. 
BUENDÍA MARTÍNEZ, I. (2000) La participación democrática: ¿un valor en extinción en las sociedades cooperativas? CIRIEC-España. Revista de Economía Pública, Social y Cooperativa, $\mathrm{N}^{\mathrm{o}} 34$, p. 7-21.

DEL BURGO, U. (2002) La desnaturalización de las cooperativas. Boletín de la Asociación Internacional de Derecho Cooperativo, № 36, p. 51-120.

DIVAR GARTEIZ-AURRECOA, J. (2011) Las cooperativas: una alternativa económica. Madrid: Dykinson.

DIVAR GARTEIZ-AURRECOA, J. (2013) Economía y democracia. Madrid: Dykinson.

DRIMER, B. y KAPLAN DE DRIMER, A. (1981) Las cooperativas: fundamentos, historia, doctrina. Buenos Aires: Intercoop, $3^{\mathrm{a}} \mathrm{ed}$.

ESCUELA NACIONAL DE EDUCACIÓN COOPERATIVA (2004) Valores y principios del cooperativismo. Santo Domingo; Escuela Nacional de Educación Cooperativa.

GADEA SOLER, E. (2011) Prólogo. En DIVAR GARTEIZ-AURRECOA, J. Las cooperativas: una alternativa económica. Madrid: Dykinson, p. 11-14.

GÓMEZ URQUIJO, L.T. (1998) La Alianza Cooperativa Internacional. Su desarrollo como institución y en especial como instrumento transformador de la sociedad. Vitoria-Gasteiz: Consejo Superior de Cooperativas de Euskadi.

HESSELBACH, W. (1978) Las empresas de la economía de interés general. México: Siglo XXI.

HOYT, A. (1996) And then there were seven: cooperative principles updated. Cooperative Grocer, enero/febrero, p. 18-22.

KAPLAN DE DRIMER, A. (2000) Las cooperativas ante los peligros de desnaturalización y desmutualización. Anuario de Estudios Cooperativos, No 1, p. 167-175.

MARCUS, L. (1988) Cooperatives and Basic Values. En ICA, XXIX Congress, Stockholm, July 1988, Agenda \& Reports. Geneva: ICA, p. 95-108.

MARTÍNEZ CHARTERINA, A. (1995) Los valores y los principios cooperativos. REVESCO, $\mathrm{N}^{\mathrm{o}} 41$, p. 35-45.

MARTÍNEZ CHARTERINA, A. (1996) La cooperativa como empresa y los principios cooperativos tras el congreso centenario de la ACI de Manchester. En Evolución del escenario económico. Homenaje a D. José $M^{a}$ Solozábal Barrena. Bilbao: Universidad de Deusto, p. 207-226.

MILlS, C. y DAVIES, W. (2013) Plan para una Década Cooperativa, ACI. Puede consultarse en http://ica.coop/sites/default/files/attachments/ICA\%20Blueprint\%20\%20Final\%20-\%20March\%2013\%20ES.pdf.

REVESCO No 116 - Tercer Cuatrimestre 2014 - ISSN: 1885-8031 - www.ucm.es/info/revesco 
SMITH, J., PUGA, R. y MACPHERSON, I. (eds.) (2006), Los jóvenes reinventan las cooperativas (traducción al español por Mirta VuOTTO). Buenos Aires: Prometeo.

SOMERVILLE, P. (2007) Co-operative Identity. Journal of Co-operative Studies, No 40.1, p. 5-17.

TRUJILLO DÍEZ, I.J. (2000) El valor jurídico de los principios cooperativos. A propósito de la Ley 27/1999, de 16 de julio de Cooperativas. Revista Crítica de Derecho Inmobiliario, $\mathrm{N}^{\mathrm{o}} 658$, p. $1.329-1.360$.

WATKINS, W.P. (1929) The call of Co-operation to Youth. Review of International Cooperation, $\mathrm{N}^{\circ} 22$, p. 368-371. 